\title{
Anti-Malassezia IgE in Patients with Atopic Eczema Before and After Treatment with Ketoconazole Shampoo
}

\author{
Najmosadat Atefi ${ }^{1}$, Mohammad Nabavi ${ }^{1}$, Shooka Esmaeeli ${ }^{1}$, Zahra Azizian ${ }^{1,{ }^{*}}$, Hadi Mohagheghian ${ }^{1}$ \\ and Shima Javadinia ${ }^{2}$ \\ Iran University of Medical Sciences, Tehran, Iran \\ ${ }^{2}$ Tehran University of Medical Sciences, Tehran, Iran \\ "Corresponding author: Iran University of Medical Sciences, Tehran, Iran. E-mail: azizian_z@yahoo.com
}

Received 2018 September 08; Revised 2018 October 19; Accepted 2018 October 24.

\begin{abstract}
Background: Treatment of some fungi species would result in the improvement of atopic eczema.

Objectives: In this study, the anti-Malassezia IgE in patients with atopic eczema before and after treatment with a ketoconazole shampoo was determined.

Methods: In this before-after investigation, 20 consecutive patients with atopic dermatitis referring to a teaching hospital in Tehran, Iran, in 2015 were enrolled. A ketoconazole shampoo was administered two times a week each time for 5-10 minutes. The treatment was used for two months and monthly evaluations were done. The total IgE level and anti-Malassezia IgE were compared at the beginning and the end of the study.

Results: The results demonstrated that there was a statistically significant difference in the total Ig-E level and anti-Malassezia IgE before and after treatment with ketoconazole.

Conclusions: According to the obtained results in this study, it may be concluded that ketoconazole would result in decreased anti-Malassezia IgE and total IgE level in patients with atopic eczema.
\end{abstract}

Keywords: Anti-Malassezia IgE, Atopic Eczema, Ketoconazole

\section{Background}

Atopic eczema is the most common chronic fluctuating inflammatory skin disease in childhood (1). Some foods, especially dairy products and eggs, and home allergens are common causes of eczema $(2,3)$. However, most cases of atopic eczema are relieved up to the third year of age (4). Symptoms such as erythema, scaling, and dryness in the skin are accompanied with severe itching leading to disordered sleep and thus chronic fatigue (5-8).

Despite unknown etiology, there are some possible causes including skin fungi leading to increased immune system activity $(9,10)$. Malassezia furfur is a part of normal skin flora living as a yeast, which may play a pathological role in the mycelium phase with skin involvement, leading to scaling and pigmentation $(11,12)$. Total $\operatorname{IgE}$ is a marker for severe atopic eczema. Recent studies have shown that the severity of atopic eczema is correlated with elevated total IgE in adults and children and anti-Malassezia IgE was found in $72 \%$ of adults and $40 \%$ of children (13). Two species including Globosa and Restricta are the most com- mon subtypes of Malassezia involved in the pathogenesis of atopic eczema. These yeasts can induce immunoglobulin (Ig) E-mediated and T-cell mediated immune responses, playing a great role in chronic inflammation of the skin, especially in the head and neck regions where colonization with Malassezia is at the highest level $(12,14)$. Regarding these matters, it may be hypothesized that treatment of these fungi would result in the improvement of atopic eczema. Ketoconazole is a common drug used as a shampoo.

\section{Objectives}

We conducted this study to determine the antiMalassezia IgE in patients with atopic eczema before and after treatment with the ketoconazole shampoo (13).

\section{Methods}

This is a prospective interventional study. It was performed as a before-after investigation. A total of 20 consec- 
utive patients with atopic eczema referring to the Department of Dermatology at Rasoul Akram Hospital of Tehran, Iran, in 2015 were enrolled. An informed consent form was signed by each subject and the Helsinki Declaration was respected all over the study course. In addition, the study was approved by a local ethics committee. The inclusion criterion was the confirmation of atopic eczema diagnosis by dermatologists according to the criteria of Hanifin and Rajka (13) and the exclusion criteria were the lack of satisfaction and hypersensitivity to ketoconazole.

The age, gender, and severity of dermatitis and eczema were determined by the clinical examinations and interviews. In addition, the total IgE level and anti-Malassezia IgE at baseline were checked in all patients with the ELISA method. The ketoconazole shampoo was administered two times a week each time for 5 - 10 minutes. The treatment continued for two months. The total IgE level and anti-Malassezia IgE were checked after the treatment again.

Data analysis was performed among 20 subjects by SPSS (version 20.0) Software [Statistical Procedures for Social Sciences; Chicago, Illinois, USA]. The paired-Sample $t$ test was used and $P$ values of less than 0.05 were considered statistically significant. We divided the patients into two age groups of younger or older than 15 years and data analysis was performed on each group separately by SPSS. The paired correlation test was used in this step and P values of less than 0.05 were considered statistically significant.

\section{Results}

We applied the ketoconazole shampoo treatment to a total of 20 patients. The mean age of the patients was 20.94 \pm 15.48 years. Some of the main characteristics of the study population are found in Table 1.

There was a statistically significant difference in the total IgE level and anti-Malassezia IgE before and after treat-

\begin{tabular}{lc}
\hline Table 1. The Main Characteristics of the Study Population & \\
\hline Characteristics & Numbers \\
\hline Age $(\mathbf{y})$ & 11 \\
$\leq 15$ & 9 \\
\hline$>15$ & \\
\hline Sex $\quad$ Male & 4 \\
\hline Female & 16 \\
\hline History of atopic dermatitis and asthma & 16 \\
\hline Positive & 4 \\
\hline Negative & \\
\hline
\end{tabular}

\begin{tabular}{lccc}
\hline \multicolumn{1}{l}{ Table 2. The Total Ig-E Level and Anti-Malassezia IgE } & & \\
\hline IgE Level & Before Treatment & After Treatment & P-Value \\
\hline Total IgE level & $259.16 \pm 230.59$ & $197.16 \pm 204.70$ & 0.03 \\
Anti-Malassezia IgE & $71.12 \pm 49.32$ & $61.54 \pm 38.61$ & 0.01 \\
\hline
\end{tabular}

ment among the total of 20 patients according to our analysis with paired $t$-test (Table 2 ).

In order to examine the results more closely and examine the differences between children and adults, we looked at each age group separately. We used paired correlation test to assess the significance of the treatment. As shown in tables 3 and 4, in both age groups, there was a significant correlation between the IgE levels before and after treatment (Tables 3 and 4). In addition, the patients' satisfaction with the treatment was studied in order to clarify whether ketoconazole was of benefit in clearing skin lesions or not (Table 5).

\section{Discussion}

In this study, the anti-Malassezia IgE in patients with atopic eczema before and after treatment with ketoconazole shampoo was determined. It was seen that there was a significant decrease in anti-Malassezia Ig-E and in the total IgE level.

The study by Back and Bartosik (15) among 29 patients with atopic eczema demonstrated that the use of systemic ketoconazole at $200 \mathrm{mg}$ daily dose for three months resulted in decreased Ig-E level and severity of the disease. The cumulative dose was a contributing factor to the clinical response.

The study by Lintu et al. (16) assessed 80 patients with atopic eczema who had IgE against Candida albicans and Pityrosporum ovale. They also used a placebo group for making comparisons. It was seen that cases with positive IgE level decreased significantly in the systemic ketoconazole group but not in the control group. Their findings are in congruence with our findings in the current study. In our study and in other studies, there were no cases with adverse effects due to ketoconazole use, showing the high safety of using this drug with either local or systemic use in patients with atopic eczema.

Finally, according to the obtained results in this study, it may be concluded that decreasing anti-Malassezia IgE and total IgE level in patients with atopic eczema could lead to clinical improvement and treatments such as using ketoconazole may be recommended for achieving better results in these patients. However, further studies with larger sample sizes and multi-center samplings are recommended. 


\begin{tabular}{|c|c|c|c|c|c|}
\hline Variables & Mean & $\mathbf{N}$ & Standard Deviation & Correlation & P-Value \\
\hline Total IgE & & & & 0.914 & 0.001 \\
\hline Before treatment & 179.06 & 9 & 156.35 & & \\
\hline After treatment & 127.9 & 9 & 70.19 & & \\
\hline Anti-Malassezia IgE & & & & 0.845 & 0.004 \\
\hline Before treatment & 87.12 & 9 & 58.47 & & \\
\hline After treatment & 65.72 & 9 & 42.79 & & \\
\hline Variables & mean & $\mathbf{N}$ & Standard deviation & correlation & P-value \\
\hline Total IgE & & & & 0.862 & 0.001 \\
\hline Before treatment & 324.70 & 11 & 266.40 & & \\
\hline After treatment & 253.82 & 11 & 260.43 & & \\
\hline Anti-Malassezia IgE & & & & 0.740 & 0.009 \\
\hline Before treatment & 58.03 & 11 & 38.31 & & \\
\hline Aefore treatment & 58.11 & 11 & 36.59 & & \\
\hline
\end{tabular}

\begin{tabular}{lcc}
\hline Table 5. Patients' Satisfaction with Ketoconazole Treatment & \\
\hline Treatment Satisfaction & N & Percent \\
\hline $\mathbf{6 0} \%<$ & 8 & 40 \\
$\mathbf{2 0}-\mathbf{6 0} \%$ & 5 & 25 \\
$\mathbf{2 0} \%>$ & 7 & 35 \\
\hline
\end{tabular}

\section{References}

1. Horii KA, Simon SD, Liu DY, Sharma V. Atopic dermatitis in children in the United States, 1997- 2004: Visit trends, patient and provider characteristics, and prescribing patterns. Pediatrics. 2007;120(3):e527-34. doi: 10.1542/peds.2007-0289. [PubMed: 17766497].

2. Boguniewicz M, Eichenfield LF, Hultsch T. Current management of atopic dermatitis and interruption of the atopic march.J Allergy Clin Immunol. 2003;112(6 Suppl):S140-50. doi: 10.1016/j.jaci.2003.09.031. [PubMed: 14657844].

3. Cipriani F, Dondi A, Ricci G. Recent advances in epidemiology and prevention of atopic eczema. Pediatr Allergy Immunol. 2014;25(7):630-8. doi: 10.1111/pai.12309. [PubMed: 25406640].

4. Zutavern A, Hirsch T, Leupold W, Weiland S, Keil U, von Mutius E. Atopic dermatitis, extrinsic atopic dermatitis and the hygiene hypothesis: Results from a cross-sectional study. Clin Exp Allergy. 2005;35(10):1301-8. doi: 10.1111/j.1365-2222.2005.02350.x. [PubMed: 16238789].

5. Weston S, Halbert A, Richmond P, Prescott SL. Effects of probiotics on atopic dermatitis: A randomised controlled trial. Arch Dis Child. 2005;90(9):892-7. doi: 10.1136/adc.2004.060673. [PubMed: 15863468]. [PubMed Central: PMC1720555].

6. Van Velsen SG, Haeck IM, Bruijnzeel-Koomen CA. Severe atopic dermatitis treated with everolimus. J Dermatolog Treat. 2009;20(6):365-7. doi: 10.3109/09546630903085294. [PubMed: 19954394].
7. Leung DYM, Bieber T. Atopic dermatitis. The Lancet. 2003;361(9352):151-60. doi: 10.1016/s0140-6736(03)12193-9.

8. Abramovits W. Atopic dermatitis. J Am Acad Dermatol. 2005;53(1 Suppl 1):S86-93. doi: 10.1016/j.jaad.2005.04.034. [PubMed: 15968268].

9. Novak N, Bieber T, Leung DY. Immune mechanisms leading to atopic dermatitis. J Allergy Clin Immunol. 2003;112(6 Suppl):S128-39. doi: 10.1016/j.jaci.2003.09.032. [PubMed: 14657843].

10. Jansen CT, Haapalahti J, Hopsu-Havu VK. Immunoglobulin E in the human atopic skin. Archiv fur dermatologische Forschung. 1973;246(4):299-302.

11. Bayrou O, Pecquet C, Flahault A, Artigou C, Abuaf N, Leynadier F. Head and neck atopic dermatitis and malassezia-furfur-specific IgE antibodies. Dermatology. 2005;211(2):107-13. doi: 10.1159/000086438. [PubMed: 16088155].

12. Nakabayashi A, Sei Y, Guillot J. Identification of Malassezia species isolated from patients with seborrhoeic dermatitis, atopic dermatitis, pityriasis versicolor and normal subjects. Med Mycol. 2000;38(5):33741. [PubMed: 11092380].

13. Glatz M, Buchner M, von Bartenwerffer W, Schmid-Grendelmeier P, Worm M, Hedderich J, et al. Malassezia spp-specific immunoglobulin $\mathrm{E}$ level is a marker for severity of atopic dermatitis in adults. Acta Derm Venereol. 2015;95(2):191-6. doi:10.2340/00015555-1864. [PubMed: 24696225].

14. Aspres N, Anderson C. Malassezia yeasts in the pathogenesis of atopic dermatitis. Australas J Dermatol. 2004;45(4):199-205. quiz 206-7. doi: 10.1111/j.1440-0960.2004.00097.x. [PubMed: 15527428].

15. Back O, Bartosik J. Systemic ketoconazole for yeast allergic patients with atopic dermatitis. J Eur Acad Dermatol Venereol. 2001;15(1):34-8. [PubMed: 11451319].

16. Lintu P, Savolainen J, Kortekangas-Savolainen O, Kalimo K. Systemic ketoconazole is an effective treatment of atopic dermatitis with IgE-mediated hypersensitivity to yeasts. Allergy. 2001;56(6):5127. [PubMed: 11421895]. 